\title{
El personaje sabio en El niño que vivía en dos casas, de Julieta Pinto
}

\author{
Silvia Méndez Anchía* \\ Recibido: Julio 2012 • Aceptado: Agosto 2012 \\ RESUMEN
}

Ciertos sucesos de la vida de una niña o niño sobre los cuales se guarda silencio, pueden inhibir su desarrollo emocional y su aprendizaje. Se propone, en este ensayo, que algunos textos literarios ofrecen estrategias para afrontar situaciones conflictivas, tales como la separación de los progenitores. Se analiza la obra El niño que vivía en dos casas, de la costarricense Julieta Pinto, y se establece que el personaje sabio de este relato presenta ocho estrategias para comprender el divorcio. Se finaliza recomendando el trabajo en el aula con textos literarios con el fin de humanizar, mediante la palabra, experiencias que afectan el desarrollo emocional y cognitivo del estudiantado.

Palabras clave: Julieta Pinto, literatura costarricense, El niño que vivía en dos casas, divorcio, personaje sabio.

\begin{abstract}
Certain events in the life of a boy and a girl which are kept in silence can inhibit their emotional development and learning. In this essay, there are proposed some literary books which offer strategies to face problematic situations such as the separation of the parents. It is analyzed the work The boy who lived in two houses from the Costa Rican Julieta Pinto, and it is established that the wise character shows eight strategies to comprehend the divorce. It ends by recommending the assignment in the classroom with literary texts in which the purpose consists on humanizing, through the word, experiences that affect the emotional and cognitive development.
\end{abstract}

Key words: Julieta Pinto, Costa Rican literature, the boy who lived in two houses, divorce, wise character.

* Filóloga y psicopedagoga. Autora de artículos sobre temas relacionados con la comprensión de lectura, el análisis literario, la producción de textos didácticos y la enseñanza de la literatura, así como de libros de texto de Español para enseñanza media. Actualmente dirige la Cátedra de Lengua y Literatura de la UNED.E-mail: smendez@uned.ac.cr 


\section{Introducción}

En Costa Rica, la tasa de divorcios se ha incrementado en un $63 \%$ en diez años: de 7000 en el 2001, subió a más de 11500 en el 2010 (La Nación, 2011).

¿Cómo afecta el divorcio a las niños y niños? Esta experiencia puede provocarles disociaciones relacionadas con tres tipos de continuidad: del cuerpo - esta tiene mayores repercusiones cuando los hijos o hijas cambian de casa, producto de la separación de sus progenitores-, de la afectividad -que se produce al alterarse la triangulación padre-madrehija o hijo-y la social -razón por la cual no se recomienda, por ejemplo, el traslado de escuela como producto de una separación de la pareja (Dolto, 1989: 21).

Dicho estado de fragmentación se agrava si predomina una actitud de silencio o mentira en relación con el divorcio. Aquellas situaciones traumáticas, sean propias o de la historia familiar de la persona, que permanecen en silencio o respecto de las cuales se miente, acaban siendo actuadas por el niño o la niña en forma de síntomas, uno de los cuales puede relacionarse con la inhibición para conocer; después de todo, el aprendizaje tiene en su base una buena cuota de curiosidad (Rojas, 2010: 31).

Para humanizar la experiencia del divorcio a los ojos de niñas y niños, es necesario que medie la palabra, ya sea de los propios progenitores -cuando se hallan en capacidad de hacerlo-, de una persona consejera, o bien, de docentes.

En ese sentido, un texto literario también puede ofrecer estrategias para afrontar la separación de los progenitores al presentar modelos y situaciones con las cuales identificarse, e iluminar así espacios de la vida de quien lee. Es posible que ese proceso de ver o entender mejor la vida propia al contrastarla con las experiencias por las que atraviesan personajes de ficción, tenga un efecto liberador o sanador. Una serie de experiencias de este tipo aplicadas a la situación del divorcio de los progenitores están recogidas en la obra de Johnston, Breunig, Garrity y Baris (2002).

$\mathrm{Si}$ bien es cierto los niños y las niñas pueden leer textos expositivos acerca de los distintos tipos de familia, este discurso resultará menos significativo que una narración en la cual un personaje de una edad cercana a la suya enfrenta una situación de divorcio y sale triunfante. Esto es lo que Doria (2011: 13) ha llamado una moraleja de esperanza:

"He comprobado que una moraleja de esperanza tiene más poder de inducción en la 'mente profunda' del que escucha un relato (por ejemplo, el de una oruga que tras muchas dificultades se convierte en mariposa) 
que una sesuda argumentación intelectual del porqué aguantar los momentos difíciles de la vida y, además, sonreír desde el alma."

En el ámbito de los estudios acerca del funcionamiento cerebral, se ha descubierto que, al entrar en contacto con textos de ficción, el lector hace una simulación mental de las acciones y sensaciones expresadas en el texto. "Las palabras del escritor actúan como un catalizador en la mente del lector -señala Carr, 2011: 96-, inspirándole nuevas ideas, asociaciones y percepciones, a veces incluso epifánicas." Una determinada narración literaria puede ofrecer, a las niñas y niños que la leen, nuevas formas de comprender una situación como el divorcio, a la luz de las experiencias y sentimientos recreados por aquella.

Justamente en la lista de lecturas aprobadas por el Consejo Superior de Educación en mayo del 2010 (MEP, Consejo Superior de Educación, 2010), aparece, en el bloque correspondiente al segundo ciclo de la Educación General Básica, la obra El niño que vivía en dos casas, de la narradora costarricense Julieta Pinto (San José, 1922). Este texto fue publicado por vez primera en el 2002 y responde, según lo manifiesta la propia autora, a una necesidad de "suavizar" la experiencia del divorcio, que afecta profundamente a la niñez actual:
"Fíjese que yo lo escribi a mi nieto, porque él fue, él tenía necesidad de ese libro. Por eso se lo escribí y creo que lo ayudó bastante [...] Por eso yo quería publicarlo, porque hay muchos niños en familias iguales. Hay mucho matrimonio quebrado hoy día y nadie piensa en los niños, y los niños son los que más sufren: que su papá y su mamá estén en diferentes casas, que su papá no llegue a la casa. Por eso traté de suavizarlo." (En Durán, 2012)

Los textos literarios construidos a partir de esta intención didáctico-liberadora suelen presentar un personaje sabio. Este constituye una opinión de autoridad que orienta, a quien lee, en su comprensión de los hechos narrados. Representa, asimismo, un modelo de persona consejera a la cual recurrir cuando se está frente a situaciones conflictivas:

"Introducir un personaje sabio en un cuento puede fomentar la creciente capacidad del niño de elegir bien a sus mentores para que le orienten en sus decisiones, y además proporcionarle estrategias de defensa adaptadas específicamente a lo que resulta más problemático para cada niño en particular." (Johnston y otros, 2002, p. 21)

Este ensayo pretende establecer cuáles estrategias aporta el personaje sabio de El niño que 
vivía en dos casas, para comprender el divorcio.

\section{Desarrollo}

Con base en la lectura de $E l$ niño que vivía en dos casas y de algunos estudios, principalmente de orientación psicoanalítica, sobre la influencia del divorcio en hijas e hijos, se presentan, a continuación, ocho estrategias que aporta el personaje sabio de este relato.

Reconocer a la persona indicada para confiarle sus problemas

El personaje sabio de El niño que vivía en dos casas se llama Amy. Es la bisabuela de David, el protagonista del relato y cuyos padres se han divorciado.

Una característica fundamental de Amy consiste en un estrecho lazo afectivo con el niño:

"Amy, su bisabuela, lo tuvo entre sus brazos y se sintió embrujada por un lazo de amor que nació en ese día y continúa ahora, más profundo e intenso. Desde entonces lo observa en su amor por sus padres, el desgarre de un divorcio temprano, la alegría de sus días en las casas de ambos, ese pensar profundo en que no dice nada y se adivina poco." (Pinto, 2002: 20)

La cercanía emocional es uno de los rasgos más marcados en la relación abuelo(a)-nieto(a) (Triadó y Villar, 2000: 33). El hecho de que Amy pertenezca al grupo familiar del niño refuerza la continuidad afectiva, ya que este recibe el reconocimiento de su familia ampliada. Ello contribuye a marcar la presencia del lazo familiar, de modo que el niño no sienta que la ruptura de sus progenitores implica una ruptura del lazo que lo une a un grupo más grande de procedencia.

Además del vínculo afectivo, otro de los estilos de abuelo(a) corresponde a la reserva de sabiduría (Neugarten y Weinstein, citado por Triadó y Villar, 2000: 31). Amy se convierte en consejera del niño; ella le interpreta aquellas partes de la realidad familiar que el niño no alcanza a comprender. Este rasgo del personaje sabio de este relato contribuye a reforzar, como se vio en la característica anterior, el lazo familiar; comparando este estilo de abuelo(a) en relación con el rol de los progenitores, Triadó y Villar (2000: 35) apuntan que "una segunda diferencia es el énfasis en los abuelos de la vinculación con una determinada historia y tradición familiar".

Finalmente, Amy es un personaje empático y debe esta característica a su oficio de escritora. Fantín dice que "los escritores son como los niños y estoy seguro que puede escucharme" (Pinto, 2002: 14). Amy cuenta con una 
capacidad especial para ponerse en el lugar del niño; la empatía es, según Miller (1998: 69), un instrumento básico de comprensión del sufrimiento infantil y exige el no juzgarlo desde una posición adultocéntrica. Amy, además, representa un modelo de persona en quien el niño puede confiar, ya que el vínculo que establece con David se sostiene en la verdad de un asunto vital para este.

\section{Pedir consejo}

En concordancia con su rol como reserva de sabiduría, la bisabuela Amy le enseña a David una herramienta comunicativa básica para enfrentar las situaciones difíciles: pedir consejo.

“—QQué es un consejo? [pregunta el niño, y Amy responde: ]

- Son unas palabras que aclaran un problema." (Pinto, 2002: 36-37)

Esta es una de las estrategias de que este personaje sabio provee al niño y le será de utilidad a lo largo de la narración para comprender situaciones conflictivas tales como las peleas entre la madre y el padre, así como el nacimiento de una hermanita.

Los adultos suelen comunicarse con los niños desde un modelo adultocéntrico. La información fluye de modo vertical y se centra en pautas de comportamiento.
Amy, en cambio, le da al niño la posibilidad de tomar la iniciativa. Pedir consejo implica, por parte de este, la capacidad de conocer sus sentimientos, de determinar qué situación lo está afectando y de pedir ayuda a una persona de confianza.

\section{Aceptar la experiencia de vivir en dos casas}

Contar con una madre y un padre representa, para la hija o hijo, protección y seguridad. Igualmente, la casa donde habita la familia significa un lugar de protección, que se relaciona con la continuidad del cuerpo. Ante la separación de los progenitores, es común que hijas e hijos alimenten fantasías de abandono y la sensación de pérdida de la continuidad del cuerpo y de la afectividad, que se acrecienta si deben mudarse de casa.

El relato de Julieta Pinto presenta, en cambio, un mundo donde no hay desprotección parental producto de la separación de los progenitores, sino más bien la apertura de nuevos espacios.

"David es un niño muy dichoso pues
vive en dos casas, pasa unos días
con su mamá y otros con su papá.
Él no sabe cuál de las dos casas le
gusta más." (Pinto, 2002: 29)

Esta forma de presentarle, al personaje niño, su situación enfatiza en la ganancia, no en la pérdida; 
en algunos casos, un divorcio puede representar una ganancia frente a una situación familiar conflictiva.

De esta manera, se atenúa, en el niño, la sensación de haber perdido un sitio y, por el contrario, se ofrece la perspectiva de que se cuenta con dos espacios de protección. Si se tienen dos casas, se tienen dos progenitores que asumen la responsabilidad por la persona menor de edad; no hay un doble abandono, sino que se abre una doble posibilidad de vivir.

Aunque la presencia de dos casas alude a la disolución de los lazos conyugales producto del divorcio, la relación que se establece entre el niño y su madre, por un lado, y el niño y su padre, por otro, alude a la continuidad de los lazos parentales, de la cual depende, según Salzberg (1996), "el éxito en la preservación de los hijos".

\section{Mantenerse al margen de las disputas}

Colocar a los hijos e hijas en medio de las peleas que surgen tanto antes del divorcio, como mientras este sucede y luego de la separación, es una forma de violencia. Mucho más si las hijas e hijos son usados para fines propios de alguno de sus progenitores con el objeto de sacar ventaja frente al otro.
"Quisiera que mis padres no pelearan nunca, para estar yo tranquilo y ellos también. Pero como eso no puede ser, lo mejor es como dice Amy, no hacerles caso, porque la gente cuando se hace grande se vuelve muy rara." (Pinto, 2002: 41)

Amy advierte el peligro que corre David al estar en medio de las disputas y lo invita a no sentirse parte de ellas (muchos niños asumen la culpa por el divorcio de sus progenitores) liberándolo, al mismo tiempo, de la obligación de entender situaciones cuya complejidad escapa a su comprensión. Además, le ofrece una perspectiva futura donde reina la esperanza: "Amy dice que cuando sean más viejos dejarán de pelear y serán muy buenos amigos" (Pinto, 2002: 41). Sobre estos dos últimos puntos (los límites de la verdad y un futuro esperanzador) se detallará en los dos apartados que siguen.

\section{Comprender su derecho a la verdad}

Así como el ocultamiento de la verdad resulta perjudicial para el desarrollo afectivo de una niña o niño, también es muy dañina aquella que se ofrece de manera cruda, cargada de detalles que enturbian el alma infantil. Por ello se habla de "sincericidio", cuando la verdad no se administra de manera adecuada y termina traumatizando a 
la persona (Bleichmar, 2007, citado por Rojas, 2010).

En la medida en que estas verbalizaciones pertenecen a una discursividad manifiesta, son siempre falsas razones, pues se quedan con lo superficial; en fin, no explican las verdaderas causas, a nivel profundo, inconsciente, de la separación (Dolto, 1989: 34).

En el texto de Pinto (2002: 41), David anota, en relación con la situación de sus progenitores que "los míos por eso viven en casas diferentes, dice Amy que no se llevan, que son muy distintos". Estas son las palabras que el niño necesita oír, no largas explicaciones acerca de los detalles, que muchas veces contienen elementos que no apoyan el sano desarrollo emocional de la persona. En otra parte del texto, retomando esta misma idea, Amy insiste en una explicación sencilla y directa: "Tu papá y tu mamá se casaron muy enamorados y ambos deseaban un hogar con hijos donde reinara siempre la alegría; pasaron unos años y se dieron cuenta de que eran muy diferentes uno del otro y esas diferencias comenzaron a separarlos" (Pinto, 2002: 105-106).

Vislumbrar un horizonte esperanzador

En su estudio sobre la influencia de los cuentos de hadas en la psique de la niñez, Bruno Bettelheim
(1988: 189) señala la necesidad de un "final feliz", que alimenta la esperanza, frente a la realidad cruda que viven los infantes. Así, en el texto de Julieta Pinto, se plantea a David un horizonte esperanzador: Amy le augura que sus progenitores dejarán de pelear y que su nueva hermanita crecerá, él la cuidará y jugará con ella.

“-Había una vez un niño pequeño que no tenía con quien jugar cuando estaba en la casa. [...] Un día llegó una hermanita, el niño la vio crecer poco a poco, después muy de prisa y un día pudo jugar con ella. [...] El niño se sintió feliz porque había salvado a su hermanita de un golpe tan grande como el que le hubiera dado la cabeza del animal. David ríe de imaginar la furia del ternero y continúa jugando con tanto brio que la pobre Amy no puede seguirlo en su carrera de alegría." (Pinto, 2002: 64-65)

El presente, para David, está colmado de dudas e inseguridades, que la bisabuela contiene mediante su escucha atenta, a la vez que le infunde esperanza en el futuro.

\section{Mantenerse dentro de una triangulación}

Cuando los progenitores se divorcian, la hija o el hijo puede alimentar la fantasía de que ahora le corresponde ser la pareja de su madre o padre. Se recomienda, por 
lo tanto, que sepa que su madre o padre tiene una vida social y afectiva independiente de su relación con la niña o niño. Debe evitarse una exclusividad en la relación con la niña o niño, lo cual se logra con la presencia de otra persona adulta y con las "palabras que le aseguren concretamente que el adulto tiene esa relación privilegiada con otro adulto" (Dolto, 1989: 79).

En el relato de Julieta Pinto, el padre de David tiene una nueva pareja, Silvia, quien está embarazada, y su madre -según le explica Amy al niño-probablemente lo hará luego cuando tenga su propia pareja.

"Cuando llega Amy a jugar supone que David quiere hablar de su hermanita, se adelanta y le pregunta. -¿Cuándo nace tu hermanita?

-Dentro de unos días, -contesta con poco entusiasmo.

¿LLa vas a querer mucho?

-No sé.

-Seguro que sí, pues va a necesitar que la cuidés por pequeñita.

David se queda pensativo unos segundos y salta la pregunta: -Amy, ¿mamá va a tener otra hermanita?

-Por ahora no, más adelante cuando se case seguro que sí." (Pinto, 2002: 64)

En esta conversación, Amy está enfatizando en la triangulación, a la vez que está hablando con la verdad acerca de la vida que llevan los progenitores que se han separado.

Conservar la certeza del amor de sus progenitores

La ruptura conyugal no destruye la parentalidad; quienes se divorcian son solamente la madre y el padre (Salzberg, 1996). Sin embargo, en ocasiones, ya sea por el alejamiento de uno de los progenitores o porque no se le han dicho las palabras necesarias al respecto, los hijos e hijas pueden temer que sus progenitores ya no los aman o, peor aún, que han sido responsables de su separación.

El capítulo XVII de El niño que vivía en dos casas es un claro ejemplo de las palabras que, con sinceridad mas sin crudeza, y con una actitud empática hacia la niña o niño, pueden explicarle la separación de sus progenitores aclarando algo muy importante: "que siempre continúan amando a sus hijos con toda su alma" (Pinto, 2002: 106).

Con su explicación, Amy libera a David de la culpa que le mueve ese transitar de una casa a otra, con la correspondiente sensación de que abandona a uno $\mathrm{u}$ otro de sus progenitores cada vez que se lleva a cabo ese desplazamiento:

“-¿Y si papá se resiente porque un día no voy a su casa? 
-No le haces caso y pronto se le pasa el resentimiento porque te quiere igual que siempre.

- $Y$ si mamá se pone triste cuando me voy?

-Al ratito estará alegre y cuando volvás te querrá igual que siempre.

David suspira, un suspiro de alivio donde se mezclan la comprensión (a medias) de cosas incomprensibles, y el alivio de despojarse de culpas nacidas por estar con uno u otro padre, y ser feliz cuando está con cualquiera de ellos." (Pinto, 2002: 106)

De esta forma, el personaje sabio de este relato prepara al niño para aceptar la situación por la cual está pasando, para vivir, con dignidad, en las dos casas que la vida le ofrece, sin sentirse menoscabado en comparación con los otros niños y niñas que habitan con ambos progenitores bajo el mismo techo.

\section{Conclusiones}

Los tipos de familia presentes en la sociedad actual son diversos y se apartan cada día más del esquema nuclear tradicional. Uno de los factores que están influyendo de manera decisiva en esta situación es el aumento en la cantidad de divorcios, con la correspondiente recomposición del grupo familiar. Para muchos niños y niñas resulta difícil asimilar la circunstancia de vivir un tiempo con su madre y otro con su padre, de manera separada.

El personaje sabio de $E l$ niño que vivía en dos casas provee de ocho estrategias para comprender el divorcio de los progenitores: 1. reconocer a la persona indicada para confiarle sus problemas; 2. pedir consejo; 3. aceptar la experiencia de vivir en dos casas; 4. mantenerse al margen de las disputas; 5 . comprender su derecho a la verdad; 6 . vislumbrar un horizonte esperanzador; 7. mantenerse dentro de una triangulación; y 8. conservar la certeza del amor de sus progenitores.

Se recomienda al profesorado la lectura, con sus estudiantes, de textos literarios que les permitan humanizar aquellas experiencias que a estos últimos les están resultando difíciles de comprender, ya que, como bien plantea Françoise Dolto (1989: 116), "desde el momento en que el lenguaje delimita tanto las alegrías como las penas, el niño hallará en la literatura diferentes apoyos a los fantasmas que su situación particular le suscita".

\section{Referencias}

Bettelheim, B. (1988). Psicoanálisis de los cuentos de hadas (tr. Silvia Furió). Barcelona: Crítica.

Bleichmar, S. (2007). La identidad como construcción. Rotenberg, E.; Agrest, B. (comp.). Homparentalidades. Buenos Aires: Lugar. 
Carr, N. (2011). Superficiales. ¿Qué está haciendo internet con nuestras mentes? México: Taurus.

Dolto, F. (1989). Cuando los padres se separan (I. Agoff, trad.). Barcelona: Ediciones Paidós Ibérica.

Doria, J. M. (2011). Cuentos para aprender a aprender. Madrid: Gaia Ediciones.

Durán, H. (2012). Cap. 3, Julieta Pinto. Programa de Producción de Material Audiovisual. Encuentros Literarios. San José. UNED.

Johnston, J. R.; Breunig, K.; Garrity, C.; Baris, M. (2002). Cuentos para enseñar a tus hijos a entender el divorcio. Barcelona: Paidós.

La Nación (2011). Por cada dos matrimonios, hay un divorcio en Costa Rica. Recuperado de http://www.nacion. com/2011-01-12/ElPais/UltimaHora/ ElPais2649815.aspx

Miller, A. (1998). Por tu propio bien. Raíces de la violencia en la educación del niño (J. del Solar, trad.). Barcelona: Tusquets.

Ministerio de Educación Pública, Consejo Superior de Educación (2010). Acuerdo 04-25-10.

Pinto, J. (2002). El niño que vivía en dos casas. Heredia: EUNA.

Rojas, M. C. (2010). Secretos y verdades en la familia: su incidencia en las problemáticas de la niñez. Construçäo Psicopedagógica, Säo Paulo-SP, Vol. 18, núm. 16, pp. 24-33.

Salzberg, B. (1996). Los niños no se divorcian. RTS: Revista de treball social, ISSN 0212-7210, Nº. 143, 1996 , págs. 27-33 Recuperado de http://www. escuelapsicoanalitica.com/enclave/ en_clave_n_02/PDF/losninosnosedivorcian.pdf

Triadó Tur, C.; Villar Posada, F. (2000). El rol de abuelo: cómo perciben los abuelos las relaciones con sus nietos. Revista Española de Geriatría y Gerontología, 35 (S2): 30-36. 